\title{
ПРОГНОЗ КАЧЕСТВА ТОВАРНОГО СЛАНЦА НА ПЕРИФЕРИЧЕСКИХ УЧАСТКАХ ЭСТОНСКОГО МЕСТОРОЖДЕНИЯ
}

Предусмотренное долгосрочным планом развития сланцевой промышленности увеличение добычи горючего сланца в Эстонской ССР и Ленинградской области быстро приведет к тому, что резервные запасы горючего сланца в Прибалтийском сланцевом бассейне будут находиться в основном на периферических участках Әстонского месторождения, где по данным поисковых работ и предварительной| разведки Управления геологии ЭССР качество сланца в залежи хуже, а горно-геологические условия разработки сложнее. Это обстоятельство заставило провести научные исследования по прогнозированию качества товарного сланца, получаемого при разработке периферических участков Әстонского месторождения. Работа проведена совместно Кохтла-Ярвеской геологоразведочной партией Управления геологии ЭССР и Институтом геологии ЭССР и закончена в 1980 г. Прогнозирование основано на сопоставлении балансов продуктов обогащения горной массы, добываемой на трех шахтах с обогатительными фабриками, и данных, полученных фракционными анализами керновых проб промышленной пачки из скважин, пробуренных на эксплуатационных участках этих же шахт, с результатами фракционных анализов керновых проб, взятых из скважин, пробуренных на прогнозируемых участках месторождения. Применимость этого метода прогноза не подлежит сомнению, так как имеется прямая зависимость между теплотой сгорания горной массы по пластопересечению промышленной пачки и теплотой сгорания и выходом получаемого из нее товарного сланца. Этому способствуют также устойчивая в пределах всего месторождения структура промышленной пачки и постепенно и закономерно изменяющиеся мощность и качество слагающих ее слоев (рис. 1).

Рис. 1. Корреляция между мощностью и теплотой сгорания горной массы промышленной пачки горючего сланца $\mathrm{A}-\mathrm{F}$. 1 - средние значения пластово-дифференциальных опробований промышленной пачки сланща в горных выработках шахт и разрезов Эстонского месторождения, 2 - средние значения пластоводнфференциальных опробований промышленной пачки сланца по разведочным скважинам на Восточном участке южной части Эстонского месторождения,

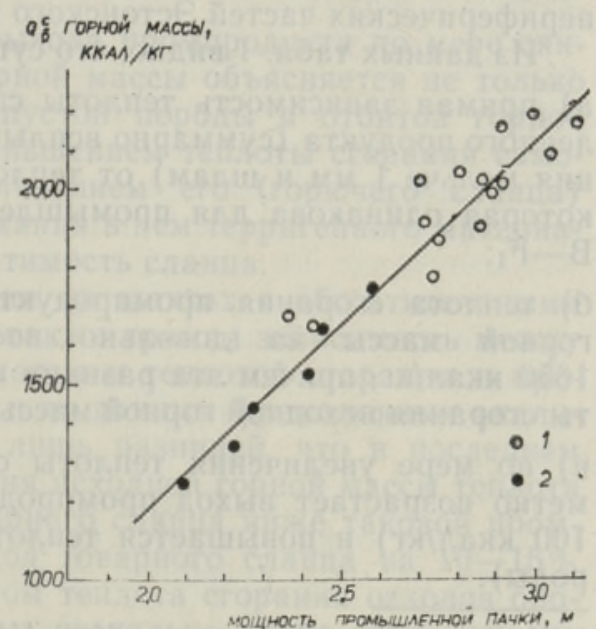


Фракционный анализ (расслоение в тяжелой жидкости плотностью 1,9 г/см ${ }^{3}$ ) керновых проб промышленной пачки в объеме слоев $A-F_{1}$ и $B-F_{1}$

\begin{tabular}{|c|c|c|c|c|c|}
\hline \multirow{3}{*}{ Местоположение } & \multirow{3}{*}{$\begin{array}{c}\text { Теплота } \\
\text { сгорания } \\
\text { исходной } \\
\text { горной } \\
\text { массы } \\
Q_{6}^{c}, \text { ккал/кг }\end{array}$} & \multicolumn{4}{|c|}{ Продукты расслоения } \\
\hline & & \multicolumn{2}{|c|}{ Промпродукт } & \multicolumn{2}{|c|}{ Порода } \\
\hline & & $Q_{6}^{\mathrm{c}}$, ккал/кr & Выход, \% & $Q_{6}^{\mathrm{c}}$, ккал/кг & Выход, \% \\
\hline \multicolumn{6}{|c|}{ Слои $\mathrm{A}-\mathrm{F}_{1}$} \\
\hline Восточный участок & $\begin{array}{l}1230^{*} \\
1290 \\
1500 \\
1500^{*} \\
1620\end{array}$ & $\begin{array}{l}2630 \\
2770 \\
2990 \\
2900 \\
3040\end{array}$ & $\begin{array}{l}38,8 \\
38,0 \\
43,6 \\
44,0 \\
46,4\end{array}$ & $\begin{array}{l}350 \\
310 \\
360 \\
390 \\
400\end{array}$ & $\begin{array}{l}61,2 \\
62,0 \\
56,4 \\
56,0 \\
53,6\end{array}$ \\
\hline $\begin{array}{l}\text { Шахты: } \\
\text { «Эстония» } \\
\text { «Виру» } \\
\text { «Эстония» } \\
\text { «Таммику» } \\
\text { «Виру» } \\
\text { «Таммику» }\end{array}$ & $\begin{array}{l}1880 \\
1980 \\
2050 \\
2120 \\
2210 \\
2320\end{array}$ & $\begin{array}{l}3530 \\
3570 \\
3560 \\
3760 \\
3790 \\
3970\end{array}$ & $\begin{array}{l}45,3 \\
47,6 \\
49,9 \\
49,4 \\
51,9 \\
52,2\end{array}$ & $\begin{array}{l}530 \\
530 \\
550 \\
510 \\
510 \\
530\end{array}$ & $\begin{array}{l}54,9 \\
52,4 \\
50,1 \\
50,6 \\
48,1 \\
47,8\end{array}$ \\
\hline \multicolumn{6}{|c|}{ Слои В-F } \\
\hline Восточный участок & $\begin{array}{l}1360 \\
1390^{*} \\
1490 \\
1670^{*} \\
1690\end{array}$ & $\begin{array}{l}2800 \\
2710 \\
2980 \\
3080 \\
3105\end{array}$ & $\begin{array}{l}39,5 \\
43,3 \\
41,2 \\
47,8 \\
47,6\end{array}$ & $\begin{array}{l}430 \\
350 \\
440 \\
410 \\
410\end{array}$ & $\begin{array}{l}60,5 \\
56,7 \\
58,8 \\
52,2 \\
51,4\end{array}$ \\
\hline $\begin{array}{l}\text { Шахты: } \\
\text { «Эстония» } \\
\text { «Эстония» } \\
\text { «Виру» } \\
\text { «Таммику» } \\
\text { «Виру» } \\
\text { «Таммику» }\end{array}$ & $\begin{array}{l}2050 \\
2180 \\
2180 \\
2270 \\
2340 \\
2470\end{array}$ & $\begin{array}{l}3700 \\
3700 \\
3700 \\
3860 \\
3890 \\
4090\end{array}$ & $\begin{array}{l}47,8 \\
51,5 \\
51,2 \\
52,0 \\
54,0 \\
53,9\end{array}$ & $\begin{array}{l}550 \\
580 \\
600 \\
540 \\
530 \\
580\end{array}$ & $\begin{array}{l}52,2 \\
48,5 \\
48,8 \\
48,0 \\
46,0 \\
46,1\end{array}$ \\
\hline
\end{tabular}

* Расслоение пронзводилось в жидкости плотностью $2,0 \mathrm{r} / \mathrm{cm}^{3}$.

Пример прогнозирования приводится по Восточному (Причудскому) * участку - наиболее изученному геологоразведкой среди других периферических частей Эстонского месторождения (табл. 1).

Из данных табл. 1 видно, что существует

a) прямая зависимость теплоты сгорания и процента выхода промышленного продукта (суммарно всплывшая фракция класса $1-25$ мм, фракция мельче 1 мм и шлам) от теплоты сгорания исходной горной массы, которая одинакова для промышленной пачки в объеме слоев $\mathrm{A}-\mathrm{F}_{1}$ и $\mathrm{B}-\mathrm{F}_{1}$;

б) теплота сгорания промпродукта выше теплоты сгорания исходной горной массы на довольно постоянную величину, равную 1400 1650 ккал/кг, причем эта разница возрастает по мере увеличения теплоты сгорания исходной горной массы;

в) по мере увеличения теплоты сгорания исходной горной массы заметно возрастает выход промпродукта (примерно на $1,4 \%$ на каждые 100 ккал/кг) и повышается теплота сгорания утонувшей фракции (породы).

* Местоположение участка см. «Изв. АН ЭССР. Геология», 1982, т. 31, № 4, с, 145. 
Средние данные по балансам продуктов обогащения горной массы на обогатительных фабриках сланцевых шахт «Ахтме» (обогащение методом мокрой отсадки), «Таммику», «Виру», «Эстония» и «Ленинградская» (обогащение в тяжелых средах плотностью $\left.1,9-2,1 \mathrm{r} / \mathrm{cm}^{3}\right)$ за период $1964-1977$ гг.

\begin{tabular}{|c|c|c|c|c|c|c|}
\hline \multirow{3}{*}{ Шахта } & \multirow{3}{*}{$\begin{array}{c}\text { Теплота } \\
\text { сгорания } \\
\text { исходной } \\
\text { горной } \\
\text { массы } Q_{6}^{\mathrm{c}} \text {, } \\
\text { ккал/кг }\end{array}$} & \multicolumn{4}{|c|}{ Продукты обогащения } & \multirow{3}{*}{ 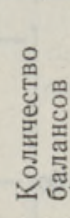 } \\
\hline & & \multicolumn{2}{|c|}{ Товарный сланец } & \multicolumn{2}{|c|}{ Порода } & \\
\hline & & $\begin{array}{c}Q_{6}^{\mathrm{c}}, \\
\text { ккал/кг }\end{array}$ & Выход, \% & $\begin{array}{c}Q_{6}^{\mathrm{c}}, \\
\text { ккал/кг }\end{array}$ & Выход, \% & \\
\hline $\begin{array}{l}\text { «Ленннградская» } \\
\text { «Эстония» } \\
\text { «Ахтме» } \\
\text { «Виру» } \\
\text { «Таммику» }\end{array}$ & $\begin{array}{l}1770 \\
1950 \\
2180 \\
2210 \\
2300\end{array}$ & $\begin{array}{l}2650 \\
2880 \\
3130 \\
3180 \\
3180\end{array}$ & $\begin{array}{l}60,8 \\
59,5 \\
61,9 \\
62,3 \\
66,0\end{array}$ & $\begin{array}{l}460 \\
580 \\
670 \\
630 \\
590\end{array}$ & $\begin{array}{l}39,5 \\
40,5 \\
38,1 \\
37,7 \\
34,0\end{array}$ & $\begin{array}{r}5 \\
3 \\
10 \\
17 \\
16\end{array}$ \\
\hline
\end{tabular}

Таблица 3

Изменение теплоты сгорания и выхода промпродукта (фактические данные по фракционным анализам керновых проб) и товарного сланца (прогноз) в зависимости от теплоты сгорания исходной горной массы промышленной пачки в объеме слоев $\mathrm{B}-\mathrm{F}_{1}$ и $\mathrm{A}-\mathrm{F}_{1}$ на Восточном участке Эстонского месторождения

\begin{tabular}{|c|c|c|c|c|c|}
\hline \multirow{3}{*}{ Слои } & \multirow{3}{*}{$\begin{array}{l}\text { Теплота сго- } \\
\text { рания исход- } \\
\text { ной горной мас- } \\
\text { сы } Q_{6}^{\mathrm{c}} \text {, ккал/кг }\end{array}$} & \multirow{2}{*}{\multicolumn{2}{|c|}{$\begin{array}{c}\text { Фактические данные } \\
\text { Промпродукт }\end{array}$}} & \multicolumn{2}{|c|}{ Прогноз } \\
\hline & & & & Товарнь & сланец \\
\hline & & $Q_{6}^{\mathrm{c}}$, ккал/кг & Выход, \% & $Q_{6}^{\mathrm{c}}$, ккал/кг & Выход, \% \\
\hline$A-F_{1}$ & $\begin{array}{l}1230 \\
1290 \\
1500 \\
1500 \\
1620\end{array}$ & $\begin{array}{l}2630 \\
2770 \\
2900 \\
2990 \\
3040\end{array}$ & $\begin{array}{l}38,8 \\
38,0 \\
44,0 \\
43,6 \\
46,4\end{array}$ & $\begin{array}{l}1970 \\
2080 \\
2350 \\
2350 \\
2500\end{array}$ & $\begin{array}{l}48,5 \\
49,5 \\
52,5 \\
52,5 \\
54,5\end{array}$ \\
\hline $\mathrm{B}-\mathrm{F}_{1}$ & $\begin{array}{l}1360 \\
1390 \\
1490 \\
1670 \\
1690\end{array}$ & $\begin{array}{l}2800 \\
2710 \\
2980 \\
3080 \\
3110\end{array}$ & $\begin{array}{l}39,5 \\
43,5 \\
41,2 \\
47,8 \\
47,6\end{array}$ & $\begin{array}{l}2170 \\
2200 \\
2340 \\
2560 \\
2590\end{array}$ & $\begin{array}{l}50,5 \\
51,5 \\
52,5 \\
55,0 \\
55,5\end{array}$ \\
\hline
\end{tabular}

Уменьшение теплоты сгорания и выхода промпродукта по мере снижения теплоты сгорания исходной горной массы объясняется не только увеличением удельного содержания пустой породы в отбитой горной массе промышленной пачки, но и уменьшением теплоты сгорания самого горючего сланца в залежи, увеличением его (горючего сланца) объемной массы и повышением содержания в нем терригенного материала, что в совокупности ухудшает обогатимость сланца.

По балансам продуктов обогащения на шахтах с обогатительными фабриками (табл. 2) прослеживается также прямая зависимость между теплотой сгорания исходной горной массы и теплотой сгорания и процентом выхода товарного сланца, как и по данным фракционных анализов керновых проб (табл. 1), с той лишь разницей, что в последнем случае при одинаковой теплоте сгорания исходной горной массы теплота сгорания получаемого на шахтах товарного сланца ниже таковой промпродукта на $650-700$ ккал/кг, а выход товарного сланца на $10-15 \%$ больше выхода промпродукта. При этом теплота сгорания отходов обогащения на обогатительных фабриках несколько выше, чем теплота 


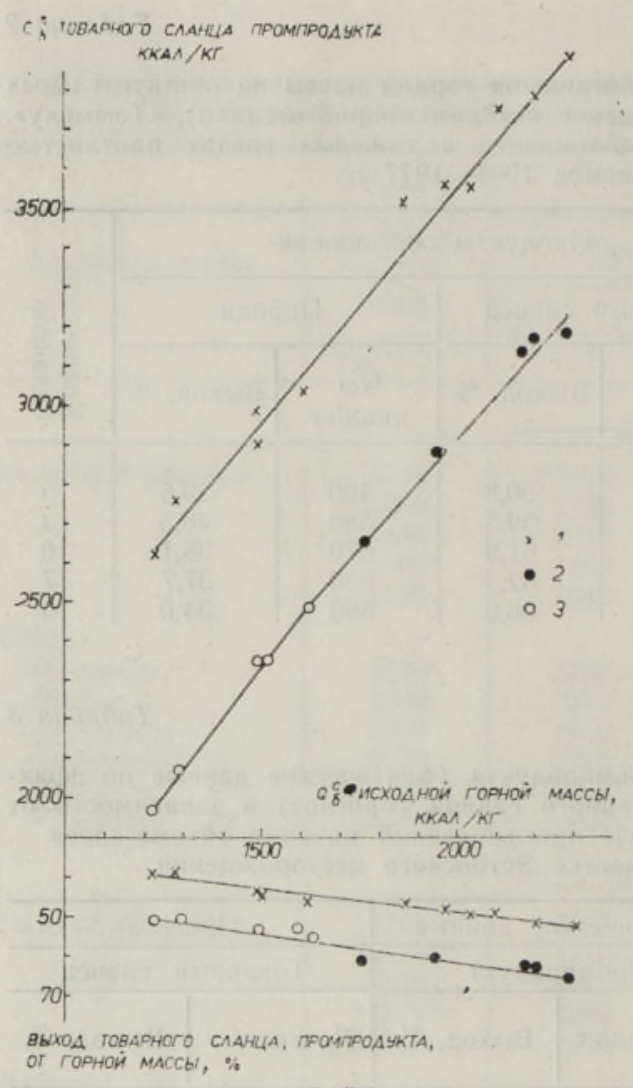

Рис. 2. Зависимость теплоты сгорания и процента выхода промпродукта по фракционным анализам и товарного сланца по балансам обогатительных фабрик от теплоты сгорания исходной горной массы промышленной пачки горючего сланца $\mathrm{A}-\mathrm{F}_{1} .1-$ промпродукт по фракционным анализам, 2 - товарный сланец по балансам обогатительных фабрик, 3 - товарный сланец по прогнозу (по данным табл. $1-3$ ).

сгорания породы. Это объясняется тем, что в обогащенном товарном сланце остается какое-то количество пустой породы, а часть сланца в процессе обогащения попадает в породные отвалы. В связи с тем, что время от времени меняется режим работы обогатительных фабрик, а также имеются некоторые различия в плотностях тяжелых сред, используемых на обогатительных фабриках и при фракционных анализах керновых проб, это нужно учитывать при прогнозировании ожидаемого качества и выхода товарного сланца на новых участках месторождения на основе данных фракционных анализов керновых проб. С учетом сказанного в табл. 3 показано, что на Восточном участке месторождения горючего сланца в объеме слоев $\mathrm{A}-\mathrm{F}_{1}$ при изменении теплоты сгорания исходной горной массы от 1620 до 1230 ккал/кг прогнозные теплота сгорания и выход товарного сланца уменьшаются соответственно от 2500 до 1970 ккал/кг и от 54,5 до $48,5 \%$. Такого же порядка цифры получены и по промышленной пачке в объеме слоев B-F 1 . Сказанное выше графически изображено на рис. 2 .

Такое прогнозирование качества и выхода товарного сланца применимо для всего Әстонского месторождения (и для Прибалтийского сланцевого бассейна в целом), поскольку строение промышленной пачки горючего сланца и характер корреляционных зависимостей между основными ее параметрами выдержаны в пределах всего месторождения.

Поскольку основными потребителями сланца, который будет добываться на периферических участках Эстонского месторождения, останутся, вероятно, крупные электростанции (прямое сжигание сланца или использование его по энерготехнологической схеме), потребляющие т. н. энергетический сорт его (<25 мм), и сланцеперерабатывающие комбинаты, потребляющие т. н. технологический сорт (25-125 мм), то практический интерес имеет прогноз теплоты сгорания и выхода товарного сланца по названным сортам (табл. 4). Из табл. 4 видно, что

а) теплота сгорания товарного сланца (3180-1950 ккал/кг) выше теплоты сгорания исходной горной массы (2300-1200 ккал/кг) на довольно постоянную величину $(750-970$ ккал/кг), причем разница уменьшается по мере снижения теплоты сгорания исходной горной массы;

б) теплота сгорания технологического сланца выше теплоты сгорания 


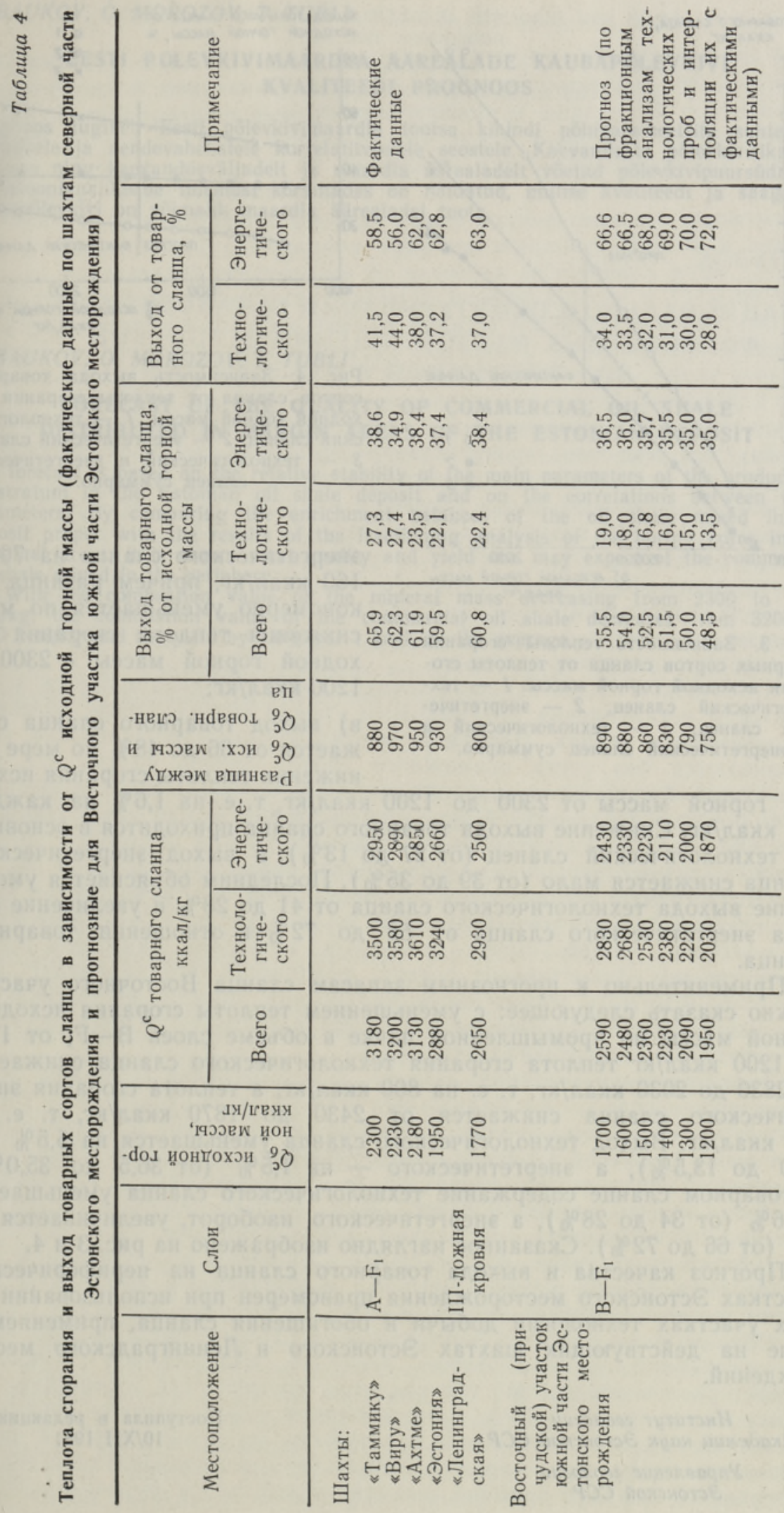




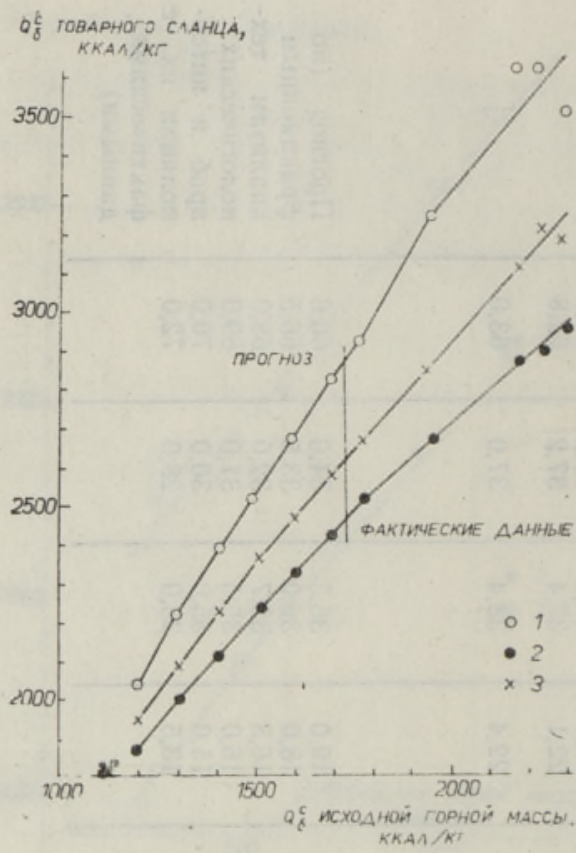

Рис. 3. Зависимость теплоты сгорания товарных сортов сланца от теплоты сгорания исходной горной массы. 1 - технологический сланец, 2 - энергетический сланец, 3 - технологический и энергетический сланец суммарно.

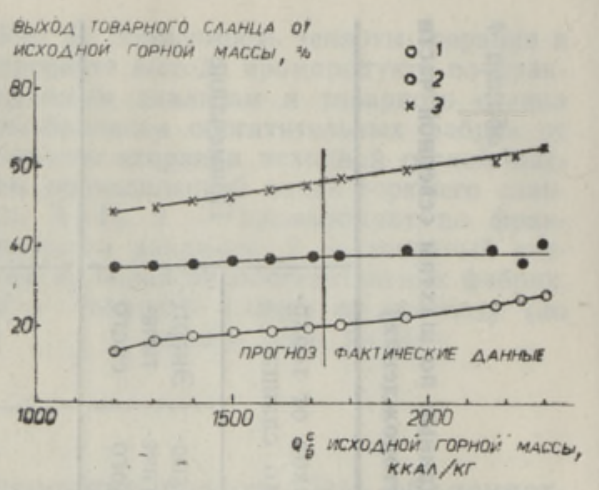

Рис. 4. Зависимость выхода товарных сортов сланца от теплоты сгорания исходной горной массы. 1 - технологический сланец, 2 - энергетнческий сланец, 3 - технологический и энергетический сланец суммарно.

энергетического сланца на 700160 ккал/кг, причем разница закономерно уменьшается по мере снижения теплоты сгорания исходной горной массы с 2300 по 1200 ккал/кг;

в) выход товарного сланца снижается от 66 до $48 \%$ по мере понижения теплоты сгорания исход-

ной горной массы от 2300 до 1200 ккал/кг, т. е. на 1,6\% на каждые 100 ккал/кг. Снижение выхода товарного сланца приходится в основном на технологический сланец (от 27 до 13\%), а выход энергетического сланца снижается мало (от 39 до $35 \%$ ). Последним объясняется уменьшение выхода технологического сланца от 41 до $28 \%$ и увеличение выхода энергетического сланца от 58 до $72 \%$ в отношении товарного сланца.

Применительно к прогнозным запасам сланца Восточного участка можно сказать следующее: с уменьшением теплоты сгорания исходной горной массы по промышленной пачке в объеме слоев $\mathrm{B}-\mathrm{F}_{1}$ от 1700 до 1200 ккал/кг теплота сгорания технологического сланца снижается от 2830 до 2030 ккал/кг, т. е. на 800 ккал/кг, а теплота сгорания энергетического сланца снижается от 2430 до 1870 ккал/кг, т. е. на 560 ккал/кг. Выход технологического сланца уменьшается на 5,5\% (от 19,0 до $13,5 \%$ ), а энергетического - на $1,5 \%$ (от 36,5 до $35,0 \%$ ). В товарном сланце содержание технологического сланца уменьшается на $6 \%$ (от 34 до $28 \%$ ), а энергетического, наоборот, увеличивается на $6 \%$ (от 66 до $72 \%$ ). Сказанное наглядно изображено на рис. 3 и 4.

Прогноз качества и выхода товарного сланца на периферических участках Эстонского месторождения правомерен при использовании на этих участках технологии добычи и обогащения сланца, применяемой ныне на действующих шахтах Әстонского и Ленинградского месторождений.

\footnotetext{
Институт геологии

Академии наук Эстонской ССР

Управление геологии Эстонской ССР
}

Поступила в редакцию 


\section{EESTI PÓLEVKIVIMAARDLA ÅRREALADE KAUBAPÓLEVKIVI KVALITEEDI PROGNOOS}

Prognoos tugineb Eesti põlevkivimaardla tootsa kihindi põhiparameetrite suhtelisele püsivusele ja nendevahelistele korrelatiivsetele seostele. Kaevanduste põlevkivirikastusbilansse ning kaevandusväljadelt ja maardla äärealadelt võetud põlevkivipuursüdamike fraktsioonianalüüside tulemusi kōrvutades on näidatud, millise kvaliteedi ja saagisega kaubapõlevkivi on võimalik maardla äärealadel toota.

S. BAUKOV, O. MOROZOV, T. TUBLI

\section{FORECAST OF THE QUALITY OF COMMERCIAL OIL SHALE DISTRIBUTED IN MARGIN AREAS OF THE ESTONIAN DEPOSIT}

The forecast is based on the relative stability of the main parameters of the productional stratum in the Estonian oil shale deposit and on the correlations between those parameters. By comparing the enrichment balances of the oil shale mined in the deposit proper with the results of the fractioning analysis of the boring cores in the marginal areas, it is shown what quality and yield one may expect of the commercial oil shale mined in the periphery.

With the combustion value of the mineral mass decreasing from 2300 to 1200 $\mathrm{kcal} / \mathrm{kg}$, the combustion value of the commercial oil shale decreases from 3200 to $1950 \mathrm{kcal} / \mathrm{kg}$ and the yield by $1.6 \%$ per $1 \mathrm{kcal}$, on the average. 